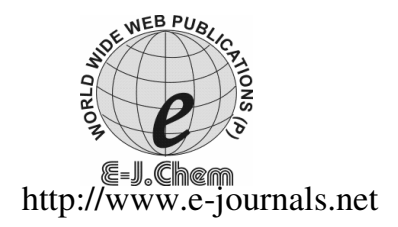

ISSN: 0973-4945; CODEN ECJHAO

E-Journal of Chemistry 2010, 7(1), 171-179

\title{
Rheokinetic Analysis of Hydroxy Terminated Polybutadiene Based Solid Propellant Slurry
}

\author{
ABHAY K MAHANTA, MONIKA GOYAL and DEVENDRA D PATHAK* \\ Defence Research \& Development Organization, \\ SF Complex, Jagdalpur-494001, India. \\ *Department of Applied Chemistry, Indian School of Mines, \\ Dhanbad-826004, India. \\ ddpathak@yahoo.com
}

Received 26 June 2009; Accepted 20 August 2009

\begin{abstract}
The cure kinetics of propellant slurry based on hydroxy-terminated polybutadiene (HTPB) and toluene diisocyanate (TDI) polyurethane reaction has been studied by viscosity build up method. The viscosity $(\eta)$-time (t) plots conform to the exponential function $\eta=a^{b t}$, where $a \& b$ are empirical constants. The rate constants $(\mathrm{k})$ for viscosity build up at various shear rate (rpm), evaluated from the slope of $\mathrm{d} \eta / \mathrm{dt}$ versus $\eta$ plots at different temperatures, were found to vary from 0.0032 to $0.0052 \mathrm{~min}^{-1}$. It was observed that the increasing shear rate did not have significant effect on the reaction rate constants for viscosity build up of the propellant slurry. The activation energy $\left(\mathrm{E}_{\eta}\right)$, calculated from the Arrhenius plots, was found to be $13.17 \pm$ $1.78 \mathrm{~kJ}$ mole ${ }^{-1}$, whereas the activation enthalpy $\left(\Delta \mathrm{H}_{\eta}{ }^{*}\right)$ and entropy $\left(\Delta \mathrm{S}_{\eta}{ }^{*}\right)$ of the propellant slurry, calculated from Eyring relationship, were found to be $10.48 \pm 1.78 \mathrm{~kJ}$ mole $^{-1}$ and $-258.51 \pm 5.38 \mathrm{~J}_{\text {mole }}^{-1} \mathrm{~K}^{-1}$, respectively. The reaction quenching temperature of the propellant slurry was found to be $-9{ }^{\circ} \mathrm{C}$, based upon the experimental data. This opens up an avenue for a "freeze-and-store", then "warm-up and cast", mode of manufacturing of very large solid rocket propellant grains.
\end{abstract}

Keywords: Rheokinetics, Propellant slurry, Reaction quenching, Polyurethane, HTPB.

\section{Introduction}

Solid propellant slurry is a colloidal suspension of rigid crystalline solid particles in a polymeric binder. It is a heterogeneous mixture of a polymeric binder usually hydroxyterminated polybutadiene ${ }^{1}$ (HTPB), a solid oxidizer (e.g. ammonium perchlorate) and a metallic fuel (e.g. aluminum) as the major ingredients. The oxidizer and metallic fuel constitute about 85 to $90 \%$ by weight of the propellant formulation. In addition to the main ingredients, other additives like curing agent (e.g. toluene diisocyanate, TDI), plasticizer (e.g. dioctyl adipate, DOA), anti-oxidant (e.g. phenyl $\beta$-napthaylamine, PBNA) and a cross-linker (e.g. butanediol-BDO and trimethylol propane-TMP) are also used to enhance the performance of solid propellant. All the ingredients, except the curing agent (diisocyanate) are mixed 
thoroughly to ensure a high degree of homogeneity of the mix. The desired quantity of diisocyanate is added and mixed thoroughly just before casting the propellant. The main reaction between the hydroxyl telechelic polymers and isocyanate compounds is given below.

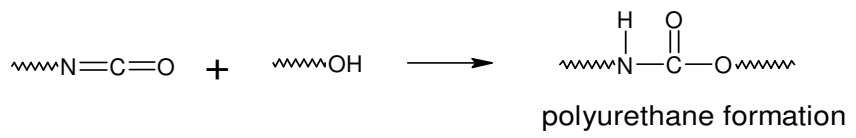

The cure reaction between the hydroxyl groups of HTPB and cross linker and isocyanate groups of TDI causes the viscosity of the slurry to increase with time. The mixed propellant must be cast before the curing reaction has progressed to the point beyond which casting is no longer possible. The time required to reach this threshold state is generally called the pot-life ${ }^{2}$ of the propellant slurry. It generally varies from 4 to 5 hours $^{2}$ depending upon the reaction kinetics and composition of the curing mass. The polyurethane cure reaction should neither be too fast or nor too slow. The solid propellant containing $85-90 \%$ solids should have enough fluidity for casting into the rocket case. One of the desired characteristics of the propellant slurry is that it should have reasonably long pot-life, particularly when large size motors are cast.

Hydroxy-terminated polybutadiene is a very popular binder used in solid rocket propellants ${ }^{1}$. The polyurethane network obtained by curing HTPB with a diisocyanate provide a matrix for inorganic oxidizer, metallic fuel and other dispersed solid components in the propellant and also serves as a fuel in solid rocket propulsion. The ultimate mechanical and thermal properties of the network formed depend on the self-life of the curing mixture. The major problem associated with HTPB based propellants is the high reactivity of primary hydroxyl groups with toluene diisocyanate (curing agent) which results in a short pot-life ${ }^{3}$. Since, a variety of additives are involved in the propellant formulation, the cure kinetics of the propellant slurry becomes even more complicated. A good understanding of the cure process is the most important prerequisite in process optimization of solid propellant manufacturing technology.

A number of studies have been conducted on the kinetics of HTPB based polyurethane cure reaction and a variety of kinetic models have been propounded to co-relate the rate of the chemical reaction with time, temperature and extent of cure ${ }^{4-8}$. However, a few studies are reported on kinetics of the propellant slurry ${ }^{9}$. Earlier, most of the studies were focused on rheological aspects of the propellant slurries ${ }^{10-13}$. Osgood ${ }^{14}$ have described the non-Newtonian nature of propellant slurry in terms of change of pseudoplasticity index with time with the progress of the curing reaction.

The present investigation was aimed at studying the cure kinetics of the HTPB based propellant slurries with toluene diisocyanate as curing agent at different shear rate (rpm) and evaluating the reaction quenching temperature of the propellant slurry so that the slurry can be stored without allowing the viscosity to build up further, in case, casting is delayed due to unavoidable circumstances during manufacturing of large solid propellant grains. Herein, we report the effect of temperature and time on the chemo-viscosity of the propellant slurry at different shear rate $(\mathrm{rpm})$. Subsequently, the rate constants $(\mathrm{k})$, activation energy $\left(\mathrm{E}_{\eta}\right)$, activation enthalpy $\left(\Delta \mathrm{H}_{\eta} *\right)$ and entropy $\left(\Delta \mathrm{S}_{\eta} *\right)$ of the curing slurry have been determined to understand the formation of polyurethane networks. These studies will be useful in effective formulation of the solid propellant without loss of material, energy and time.

\section{Experimental}

Hydroxy-terminated polybutadiene manufactured by free radical polymerization with hydroxyl value $=41 \mathrm{mg} \mathrm{KOH} / \mathrm{g}$, polydispersity $=1.70$, viscosity at $30^{\circ} \mathrm{C}=6000 \mathrm{cP}$, viscosity at $60^{\circ} \mathrm{C}=1590 \mathrm{cP}$, cis / trans / vinyl $(\%)=25 / 59 / 16$, was procured from trade. Ammonium perchlorate with purity $>99$ per cent was used in bimodal distributions having 
average particle size $300 \mu \mathrm{m}$ and $51 \mu \mathrm{m}$ respectively. Dioctyl adipate (saponification value $=301 \mathrm{mg} \mathrm{KOH} / \mathrm{g}$ ), toluene diisocyanate (purity $>99$ per cent) and aluminum powder (mean diameter $=32 \mu \mathrm{m}$ ) used as plasticizer, curator and fuel, respectively, were procured from trade. Butanediol with hydroxyl value $=1225 \mathrm{mg} \mathrm{KOH} / \mathrm{g}$ and trimethylol propane with hydroxyl value $=1222 \mathrm{mg} \mathrm{KOH} / \mathrm{g}$ was used as chain extender and cross-linking agent respectively. Particle size of ammonium perchlorate (AP) and aluminum (Al) powder were measured by CILAS particle size analyzer-1180 model.

\section{Preparation of propellant slurry}

Propellant mixing was carried out with $86 \%$ solid loading in which $68 \%$ was bimodal ammonium perchlorate with a coarse to fines ratio $4: 1$ and $18 \%$ was aluminum powder. The stochiometric ratio of the curator to binder was fixed at 0.8 for this formulation. The mixing was carried out in two phases. In the first phase, all the liquid ingredients except the curing agent were premixed thoroughly for about 30 minutes. The mixing was then continued for about $2.5 \mathrm{~h}$ upon addition of solid components. Hot water was circulated through the jacket of the mixture to maintain a constant temperature (i.e. $38 \pm 2{ }^{0} \mathrm{C}$ ) throughout the mixing cycle. A homogeneous test of the slurry was carried out after completion of the mixing cycle to confirm the uniform dispersion of $\mathrm{AP}$ and $\mathrm{Al}$ powder in the propellant mix.

In the second phase, a curing agent i.e. toluene diisocyanate (TDI) was added to the premixed slurry and mixed for 40 minutes at $40 \pm 1^{\circ} \mathrm{C}$. Three propellant slurry samples were taken in $500 \mathrm{~mL}$ container of $84 \mathrm{~mm}$ diameter and $110 \mathrm{~mm}$ length and kept in thermostate water bath (Brookfield) separately at $40^{\circ}, 50^{\circ}$ and $60^{\circ} \mathrm{C}$.

\section{Measurement of viscosity build-up}

The viscometer used to measure the viscosity of the curing slurry was a rotational type digital Brookfield viscometer model HADV-II + . The viscometer was mounted to a motorized stand (helipath stand), which slowly raises and lowers the viscometer at the rate of 7/8-inch per minute. The helipath stand was used during the measurement of viscosity to eliminate the channeling effect caused due to rotation of the spindle inside the propellant slurry. The viscosity was measured by using T-E spindle at three different temperatures. The spindle was attached to the lower shaft of the viscometer and centered in the propellant slurry. Initially, it was immersed about $7 \mathrm{~mm}$ to the propellant slurry by using the helipath stand. The rotational speed was adjusted at $0.5 \mathrm{rpm}$. After one complete rotation, readings were recorded at an interval of onesecond at $0.5,1,2.5,5$ and $10 \mathrm{rpm}$ (20 readings with each rpm) by the wingather software. Viscosity values at a specific rotational speed were averaged and used in the data analysis.

\section{Results and Discussion}

\section{Determination of reaction rate constant $(k)$ at various shear rate (rpm)}

The viscosity of the curing slurry was measured at different time intervals with various $\operatorname{rpm}(\mathrm{s})$. Figure 1 shows the viscosity $(\eta)$-time $(\mathrm{t})$ plots for the slurry at $40^{\circ}, 50^{\circ}$ and $60^{\circ} \mathrm{C}(\eta$ at $0.5 \mathrm{rpm}$ ). A mathematical relationship between viscosity and time was obtained by fitting the data to an exponential function of the type $\eta=\mathrm{ae}^{\mathrm{bt}}\left(\mathrm{R}^{2}=0.98-0.99\right)$ by the method of least squares, where a \& b are empirical constants. The relationship thus obtained is given in Table 1 . From this relationship, the rates of viscosity build up $(\mathrm{d} \eta / \mathrm{dt})$ were computed at different time intervals. Figure 2 shows the plot of $\mathrm{d} \eta / \mathrm{dt}$ versus $\eta$ at three different temperatures. A good linearity of these plots implies that the viscosity build up is of the first order process. Since, the rate of viscosity build up depends on the extent of cure reaction taking place at time " $\mathrm{t}$ ", 
it could be regarded as the measure of concentration of the species responsible for cure reaction at the corresponding time ${ }^{4}$. Thus, the slope of the rate of viscosity build up $(\mathrm{d} \eta / \mathrm{dt})$ versus viscosity $(\eta)$ plot could be considered as the measure of rate constant $(k)$ for the viscosity build up. The rate constants, thus obtained, at different $\mathrm{rpm}(\mathrm{s})$ are listed in Table 1 .

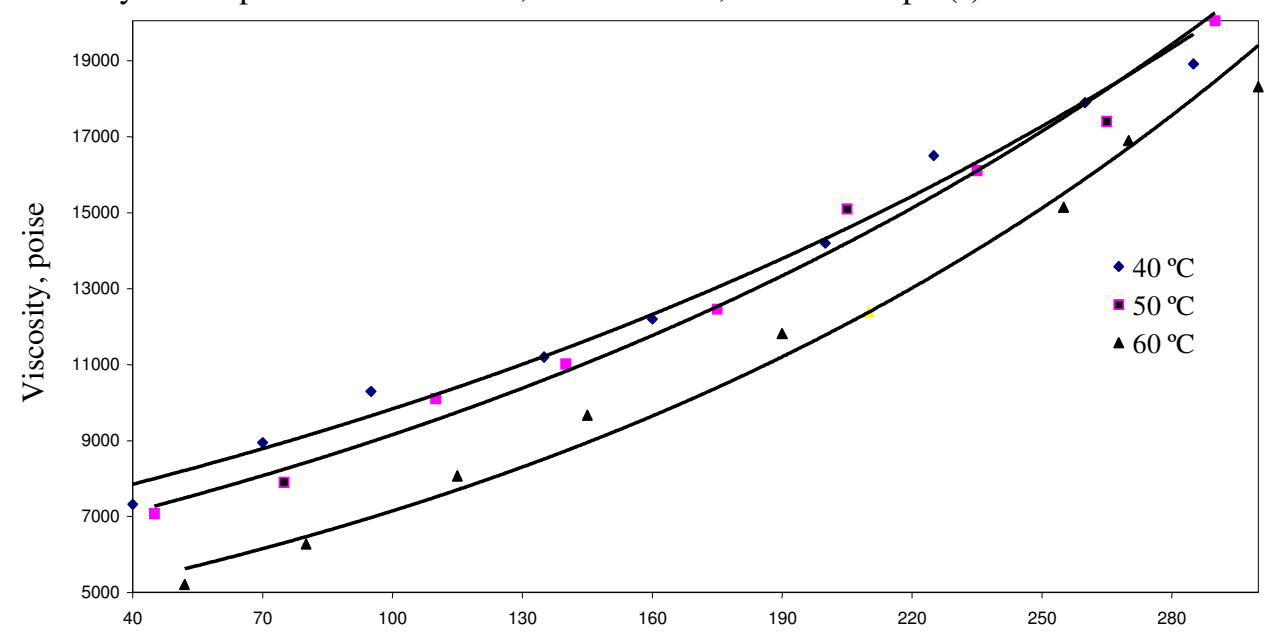

Figure 1. Plots of viscosity $(\eta) v s$. time $(\mathrm{t})$ of the propellant slurry at three different temperatures.

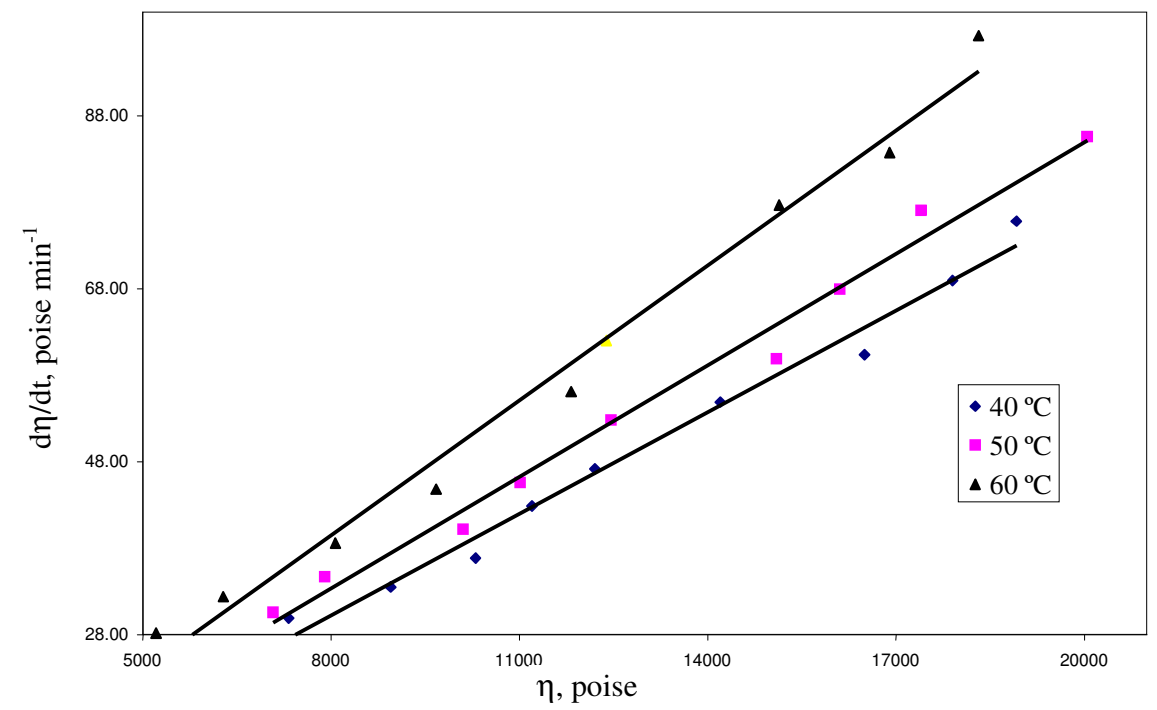

Figure 2. Plots of $\mathrm{d} \eta / \mathrm{dt} v s . \eta$ of the propellant slurry at three different temperatures.

\section{Casson model and rheokinetics of the slurry from infinite shear viscosity}

Casson ${ }^{15}$ proposed an equation to relate the shear stress to shear rate of pigment-oil suspension of the printing ink type. Asbeck ${ }^{16}$ has subsequently modified this equation as $\eta^{1 / 2}=\eta_{\infty}{ }^{1 / 2}+\tau_{0}{ }^{1 / 2} \gamma^{-1 / 2}$, where $\eta$ is the viscosity, $\eta_{\infty}$ is the infinite shear viscosity, $\tau_{0}$ is the yield point and $\gamma$ is the shear rate. The plot of $\eta^{1 / 2}$ against $\gamma^{-1 / 2}$ should, therefore, yield a 
straight line. The slope and intercept of the straight line gives the value of $\tau_{0}{ }^{1 / 2}$ and $\eta_{\infty}{ }^{1 / 2}$. The two parameters $\eta_{\infty}$ and $\tau_{0}$ can be related to the product performance and composition variations ${ }^{17}$. The viscosity of the curing slurry at any given time (t) could be related to the shear rate (rpm) by Casson equation. Figure 3 shows the isochrones plot of square root of viscosity $\left(\eta^{1 / 2}\right)$ versus square root of reciprocal shear rate in $\operatorname{rpm}\left(\gamma^{-1 / 2}\right)$ of the propellant slurry. The intercepts of these plots give the values of $\eta_{\infty}{ }^{1 / 2}$. The infinite shear viscosity $\left(\eta_{\infty}\right)$, thus, obtained was plotted against the corresponding time and a mathematical relationship of exponential type was obtained by the least squares algorithm. From this relationship the rate of viscosity build up $\left(\mathrm{d} \eta_{\infty} / \mathrm{dt}\right)$ was calculated and plotted against the corresponding viscosity $\left(\eta_{\infty}\right)$ to determine the value of $k_{\infty}$. The rate constants thus obtained at three different temperatures are given in Table 1. It is seen that the values of $\mathrm{k}_{\infty}$ at all the temperatures studied are lesser as compared to that of low shear rate.

Table 1. Empirical constants and reaction rate constants of the propellant slurry at different $\operatorname{rpm}(\mathrm{s})$.

\begin{tabular}{cccccccccc}
\hline Temp. & \multicolumn{2}{c}{$\eta_{0.5}=\mathrm{ae}^{\mathrm{bt}}$} & \multicolumn{8}{c}{ Rate Constants $(\mathrm{k}) \times 10^{2}\left(\mathrm{~min}^{-1}\right)$} & \\
\cline { 2 - 10 }${ }^{\circ} \mathrm{C}$ & $\mathrm{a}$ & $\mathrm{b}$ & $\mathrm{k}_{0.5}$ & $\mathrm{k}_{1}$ & $\mathrm{k}_{2.5}$ & $\mathrm{k}_{5}$ & $\mathrm{k}_{10}$ & $\mathrm{k}_{\infty}$ & $\mathrm{k}_{\mathrm{avg}} \pm \sigma$ \\
\hline 40 & 6755.9 & 0.0038 & 0.39 & 0.37 & 0.37 & 0.37 & 0.36 & 0.32 & $0.36 \pm 0.02$ \\
50 & 6028.5 & 0.0042 & 0.43 & 0.44 & 0.47 & 0.43 & 0.42 & 0.43 & $0.44 \pm 0.02$ \\
60 & 4341.4 & 0.0050 & 0.52 & 0.52 & 0.48 & 0.50 & 0.47 & 0.46 & $0.49 \pm 0.03$ \\
\hline
\end{tabular}

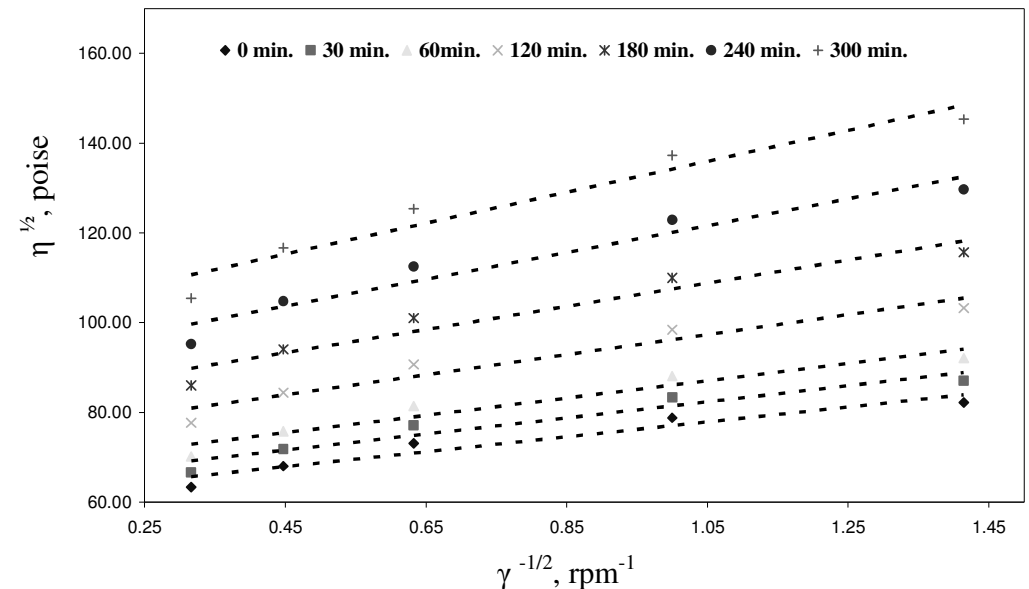

Figure 3. Casson plots of $\eta^{1 / 2} v s \cdot \gamma^{-1 / 2}$ of the propellant slurry at $40^{\circ} \mathrm{C}$.

\section{Effect of shear rate on viscosity and kinetics of the propellant slurry}

It is observed that an increase in shear rate reduces the viscosity of the propellant slurry. This could be due to the fact that solid propellant slurry is a two-phase system, i.e. a binder phase and a dispersed phase of solid particles. The viscosity of the slurry is the net effect of the continuous binder phase, dispersed particulate solids, various cohesive and adhesive forces operating between the ingredients and progress of chemical cross-linking between reactive species of the binder and the curator. The particles of the solid phase forms aggregates due to various adhesive and cohesive forces between the ingredients and when flocs (clumps) are aggregated in a dispersion system, the effect of shearing on aggregates can result in shear thinning (pseudoplastic) behavior. At low shear rate, the aggregates may be deformed but remains essentially intact. As the shear rate is increased, the aggregates may be broken down into individual flocs, thus, decreasing the viscosities of the slurry (shear thinning behavior). 
The effect of increasing shear rate on reaction kinetics is, generally, to increase the rate of the reaction. This is due to the increase in mobility of the reactive species during shearing. However, it can be seen from Table 1 that at low temperature $\left(40{ }^{\circ} \mathrm{C}\right)$, the viscosity build up rate constants calculated at different $\mathrm{rpm}(\mathrm{s})$ differ very slightly from each other but at higher temperature $\left(60^{\circ} \mathrm{C}\right)$, the value of rate constants at different shear rates differ quite significantly and the overall effect is a decrease in $\mathrm{k}$ with increasing shear rates. A plausible explanation for this anomalous behavior is that at higher temperature, even though the mobility of the reactive species increases due to shearing, the shear thinning phenomena of the slurry counters the influence of the shear rate on increasing the mobility of functional species. Accordingly, the effect of shear rate on increasing the mobility of the reaction species is not prominent. Therefore, the rate of the reaction is not significantly affected due to shearing. Further, the flocs begin to link together after getting broken down by high shearing action and the rate at which this occurs also affects the reaction kinetics. Propellant slurry being highly loaded with the solid particles, once the aggregates are broken down at high shear rate, the physical relinking rate of the flocs would be very slow and the increase in viscosity of the propellant slurry with time is only due to the chemical cross-linking reaction of the binder and curator resulting in reduced reaction rate as compared to that of low shear rates.

Effect of time and temperature on chemoviscosity: determination of reaction-quenching temperature and equiviscosity time

It is shown that the viscosity-time profiles of the propellant slurry obtained at three different temperatures conform to the exponential function of the type $\eta(t)=a e^{b t}$.

Taking logarithm, we get,

$$
\ln \eta(t)=\ln a+b t
$$

This implies that the plot of $\ln \eta(t) v s$. time (t) would be a straight line. Since, viscosity is also a function of temperature, the effect of temperature may be incorporated into the terms $\ln$ a and $\mathrm{b}$. Thus, we get, $\ln \eta(\mathrm{t}, \mathrm{T})=\ln \mathrm{a}(\mathrm{T})+\mathrm{b}(\mathrm{T}) \mathrm{t}$. The slope and intercept of the $\ln \eta(\mathrm{t}, \mathrm{T}) v s$. time (t) plots varies linearly with the reciprocal of temperature $(1 / T)$. Therefore, we get $\ln a(T)=m_{a} / T$ $+c_{a}$ and $b(T)=m_{b} / T+c_{b}$, where $m$ is the slope and $c$ is the intercept of the straight line of $\ln a v s$. $1 / \mathrm{T}$ and $\mathrm{b} v s .1 / \mathrm{T}$ plots (Figure 4). Substituting the value of $\ln \mathrm{a}$ and $\mathrm{b}$ in Eq. (1), we get Eq. (2).

$$
\ln \eta(t, T)=m_{a} / T+c_{a}+\left(m_{b} / T+c_{b}\right) t
$$

Partial differentiation of Eq.(2) w.r.t. time ( $\mathrm{t}$ ) and temperature (T), we would get Eq.(3) and (4)

$$
\begin{gathered}
\frac{\partial(\ln \eta(t, T))}{\partial t}=m_{b} / T+C_{b} \\
\frac{\partial(\ln \eta(t, T))}{\partial T}=-1 / T^{2}\left(m_{a}+m_{b} t\right)
\end{gathered}
$$

The values of $m_{b}$ and $c_{b}$ are substituted in Eq. (3) and $\partial \ln \eta(t, T) / \partial t$ is equated to zero. Solving for $\mathrm{T}$ gives $\mathrm{T}=264 \mathrm{~K}$ or $-9{ }^{\circ} \mathrm{C}$ for this formulation. This implies that the viscosity of the slurry remains unchanged with time at $-9{ }^{\circ} \mathrm{C}$, i.e. the reaction between $\mathrm{OH}$ and $\mathrm{NCO}$ species can be quenched, if maintained at this temperature. This gives the slurry an infinite pot-life. Similarly, setting $\partial \ln \eta(\mathrm{t}, \mathrm{T}) / \partial \mathrm{T}=0$ implies that there is no change in viscosity with temperature. This condition is satisfied when $t=6 \mathrm{~h}$. When the slurry is $6 \mathrm{~h}$ old, it's viscosity remains unperturbed for small change in temperature. Substituting, $\mathrm{t}=6 \mathrm{~h}$ and the values of $\mathrm{a}$ and $\mathrm{b}$ in the exponential equation $\eta_{0.5 \mathrm{rpm}}=\mathrm{ae}^{\mathrm{bt}}$, we get $\eta_{0.5 \mathrm{rpm}} \approx 26,500$ poise at all temperatures studied. Thus, it can be concluded that at higher temperature, the curing time of the propellant slurry can be reduced only after $6 \mathrm{~h}$. 


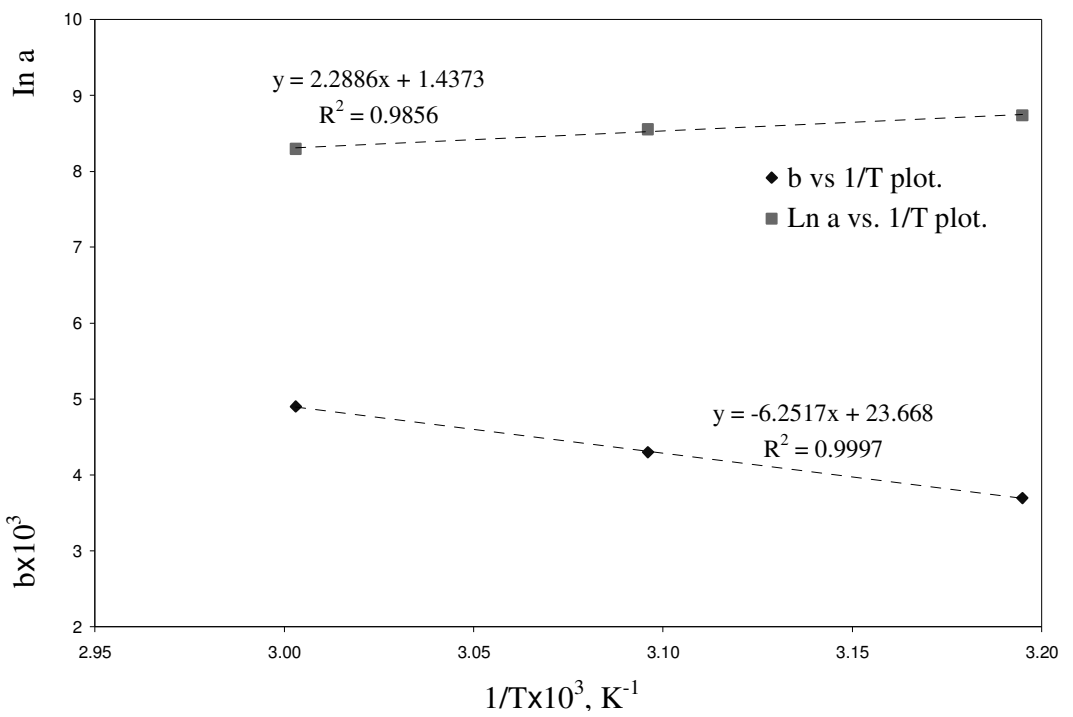

Figure 4. Plots of $\ln \mathrm{a}$ and $\mathrm{b} v s .1 / \mathrm{T}$ of the propellant slurry.

The sensitivity of rate constant $(\mathrm{k})$ to temperature change can be evaluated from $\mathrm{dk} / \mathrm{dT}$. The data in Table 1 shows that the viscosity build up rate constant increases by $1.2 \pm 0.1$ times for every $10{ }^{\circ} \mathrm{C}$ rise in temperature.

Determination of thermodynamic parameters $\left(E_{\eta}, \Delta H_{\eta}{ }^{*}\right.$ and $\left.\Delta S_{\eta}{ }^{*}\right)$

The activation energy $\left(\mathrm{E}_{\eta}\right)$, activation enthalpy $\left(\Delta \mathrm{H}_{\eta}{ }^{*}\right)$ and entropy $\left(\Delta \mathrm{S}_{\eta}{ }^{*}\right)$ of the propellant slurry are the important thermodynamic parameters that can be used to understand the reaction mechanism ${ }^{18}$. These thermodynamic parameters may also be used to optimize the cure cycle of the polymerization reaction both in terms of time and energy. To calculate the activation energy, Arrhenius plots were obtained by plotting $\ln \mathrm{k} v s$. 1/T with T expressed in Kelvin (Figure 5).

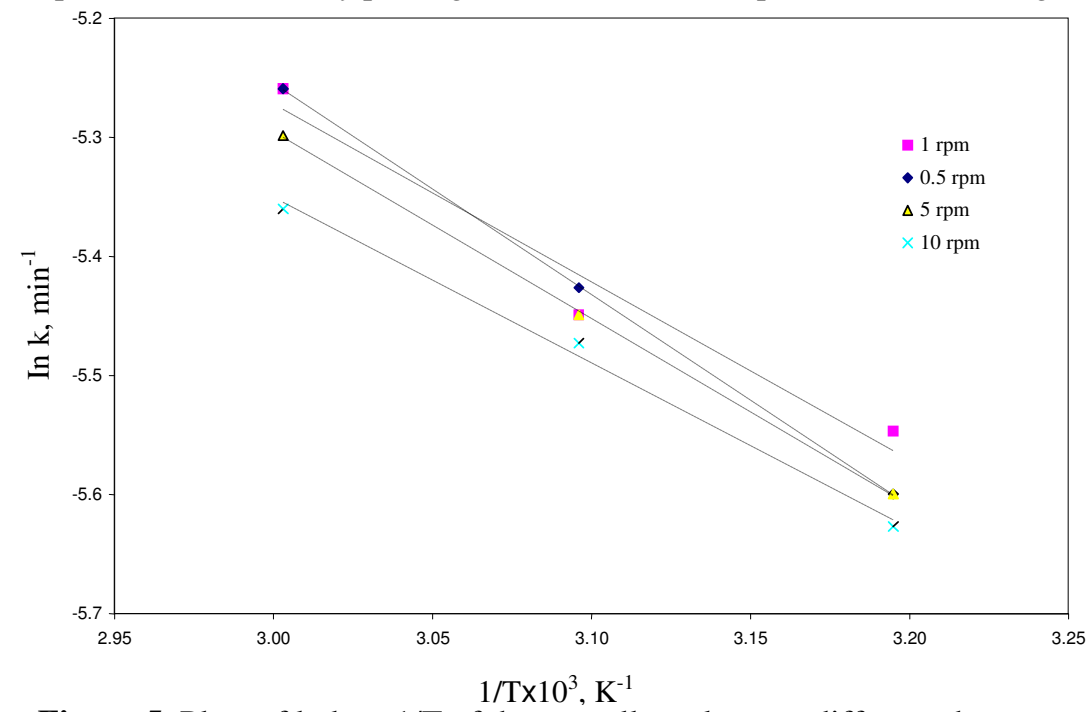

Figure 5. Plots of $\ln \mathrm{k} v s .1 / \mathrm{T}$ of the propellant slurry at different shear rate. 
The value of $E_{\eta}$ at various rpm(s) was calculated from the slopes of the straight lines thus obtained and listed in Table 2. Eyring relationship ${ }^{19}$ (Eq. (5)) was used to determine the activation enthalpy $\left(\Delta \mathrm{H}_{\eta}{ }^{*}\right)$ and entropy $\left(\Delta \mathrm{S}_{\eta}{ }^{*}\right)$ of the propellant slurry.

$$
\ln \frac{k}{T}=\ln \frac{R}{N h}+\frac{\Delta S^{*}}{R}-\frac{\Delta H^{*}}{R T}
$$

Table 2. Thermodynamic parameters $\left(\mathrm{E}_{\eta}, \Delta \mathrm{H}_{\eta}{ }^{*}\right.$ and $\left.\Delta \mathrm{S}_{\eta}{ }^{*}\right)$ of the propellant slurry at different $\operatorname{rpm}(\mathrm{s})$.

\begin{tabular}{llll}
\hline $\mathrm{rpm}(\mathrm{s})$ & $\mathrm{E}_{\eta}, \mathrm{kJ} \mathrm{mole}$ & $\Delta \mathrm{H}_{\eta}{ }^{-1}, \mathrm{~kJ} \mathrm{~mole}^{-1}$ & $\Delta \mathrm{S}_{\eta}{ }^{*}, \mathrm{~J} \mathrm{~mole}^{-1} \mathrm{~K}^{-1}$ \\
\hline 0.5 & 12.48 & 9.74 & -260.48 \\
1 & 14.74 & 12.06 & -253.37 \\
2.5 & 11.37 & 8.69 & -263.85 \\
5 & 13.04 & 10.36 & -258.81 \\
10 & 11.57 & 8.88 & -263.69 \\
$\infty$ & 15.82 & 13.14 & -250.83 \\
\hline
\end{tabular}

Where $\mathrm{T}$ is the temperature $(\mathrm{K}), \mathrm{R}=8.314 \mathrm{~J} \mathrm{~mol}^{-1} \mathrm{~K}^{-1}$ the universal gas constant, $\mathrm{k}$ is the kinetic rate constant, $\mathrm{N}=6.02 \times 10^{23}$ the Avogadro's constant and $\mathrm{h}=6.62 \times 10^{-34} \mathrm{Js}$ is the Planck's constant.

The plot of $\ln \mathrm{k} / \mathrm{T} v s .1 / \mathrm{T}$ is shown in Figure 6. The values of $\Delta \mathrm{H}_{\eta} * \& \Delta \mathrm{S}_{\eta} *$ were calculated from the slope and intercept of the straight line obtained and listed in Table 2. It is seen that the value of $\mathrm{E}_{\eta}, \Delta \mathrm{H}_{\eta} * \& \Delta \mathrm{S}_{\eta} *$ of the propellant slurry at infinite shear rate are higher as compared to that of low shear rate (rpm).

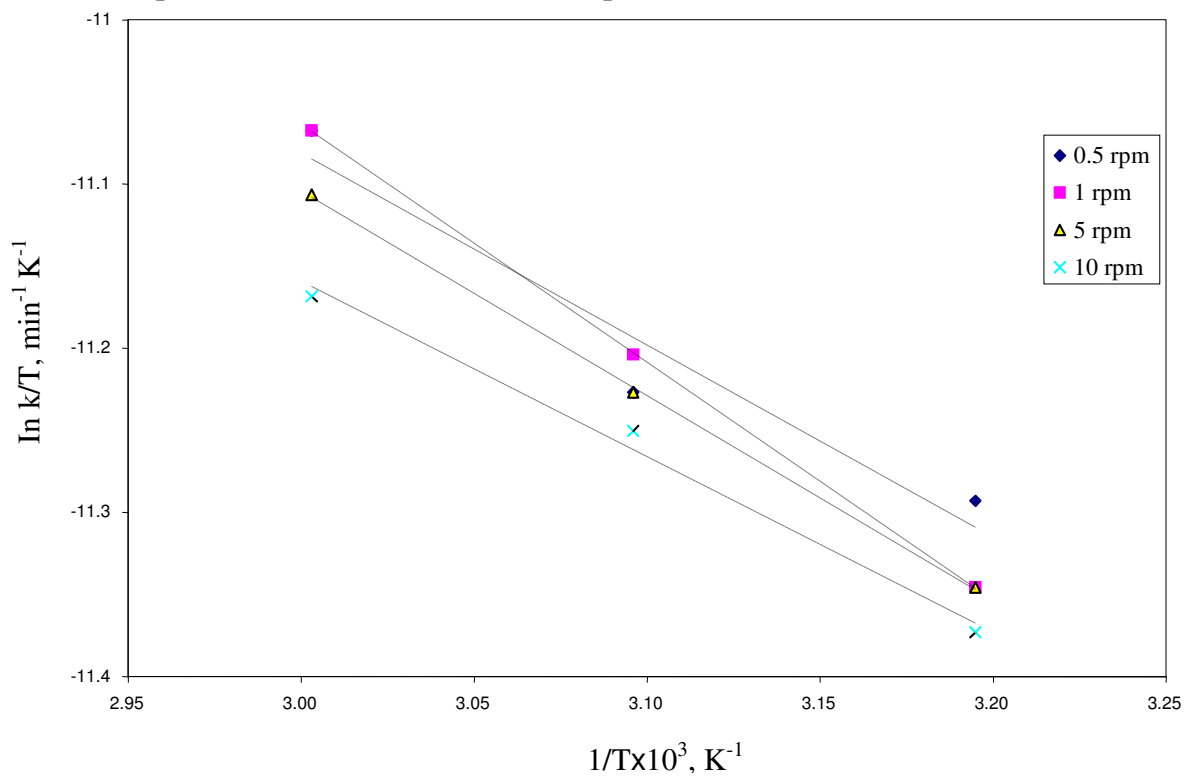

Figure 6. Plots of $\ln \mathrm{k} / \mathrm{T} v s .1 / \mathrm{T}$ of the propellant slurry at different shear rate.

\section{Conclusion}

It is shown that rate constants for viscosity build up can be calculated from the rheokinetic plots of the propellant slurry. A good linearity of the rheokinetic plots implies that the 
viscosity build up of the propellant slurry is of the first order process. The experimental results indicate that the rate of the reaction is not significantly affected by shearing. The viscosity and shear rate (rpm) data of the propellant slurry were successfully modeled by the Casson equation. The values of rate constant $(\mathrm{k})$ determined from the infinite shear viscosity of the propellant slurry were found to be lower as compared to that of low shear rate. However, the $\mathrm{E}_{\eta}, \Delta \mathrm{H}_{\eta}{ }^{*} \& \Delta \mathrm{S}_{\eta} *$ values of the slurry, calculated at high shear rate, were higher as compared to that of low shear rates. Based on the experimental data, the reaction quenching temperature of the propellant slurry was found to be $-9{ }^{\circ} \mathrm{C}$. This result is significant because during the manufacture of very large size rocket propellant grains, in case casting is delayed due to any unavoidable technical snags in cast set up, the polyurethane reaction in the propellant slurry can be frozen by maintaining/storing the slurry at the quenching temperature. The slurry may be warmed up and cast to the rocket motor case as and when required. This may obviate wastage of the propellant slurry.

\section{Acknowledgement}

The authors are thankful to Shri T Mohan Reddy, General Manager, SF Complex, Jagdalpur for his kind permission to publish this research work.

\section{References}

1. Muthiah R M, Krishnamurthy V N and Gupta B R, J Appl Polym Sci., 1992, 44, 2043.

2. Krishnamurthy V N, In Short term courses on Solid Propellant Technology, IIT, Madras, India, May 1993, 17-22.

3. Mark H F and Gaylord N G, Encyclopedia of Polymer Science and Technology, Interscience Publishers, New York, 1970, 12, 105-136.

4. Singh M, Kanungo B K and Bansal T K, J Appl Polym Sci., 2002, 85, 842-846.

5. Sekkar V, Krishnamurthy V N and Jain S R, J Appl Polym Sci., 1997,66, 1795-1801.

6. Abraham V, Scariahm K J, Bera S C , Rama Rao M and Sastri K S, Eur Polym J., 1996, 32, 79-83.

7. Kothandaraman K and Sultan N A, J Appl Polym Sci., 1993, 50, 1611-1617.

8. Coutinho F M B, Rezende L C and Quijada R C P, J Polym Sci., Part A: Polym Chem., 1986, 24, 727-735.

9. $\quad$ Lakshmi K and Athithan S K, Polym Composites, 1999, 20 (3), 346-356.

10. Mahanta A K, Dharmsaktu I and Pattnayak P K, Def Sci J., 2007, 57 (4), 581-588.

11. Muthiah R M, Manjari R, Krishnamurthi V N and Gupta B R, Polym Eng Sci., 1991, 31, 61-66.

12. Riffaud M H, Chounet G and Tauzia J M, Proc $18^{\text {th }}$ Int Conf of ICT, 1987.

13. Muthiah R M, Manjari R, Krishnamurthi V N and Gupta B R, Def Sci J., 1993, 43, 167.

14. Osgood A A, "Rheological characterisation of non-Newtonian propellant for casting optimisation" In AIAA 5 th Propulsion Joint Specialist Conference, US Air Force Academy, Colorado Springs, CO. AIAA, 1969. Paper No. 69-518.

15. Casson N and Mills C C, Pergamon Press, New York, 1959, 84.

16. Asbeck W K, Official Digest, 1961, 33(432), 65.

17. Pierce P E, J Paint Tech., 1971, 43 (557), 38.

18. Espenson $\mathrm{J} H$, Chemical Kinetics and Reaction Mechanisms, $2^{\text {nd }}$ Ed., McGraw-Hill, New York, 1990.

19. Burel F, Feldman A and Bunel C, Polymer, 2005, 46, 15-25. 


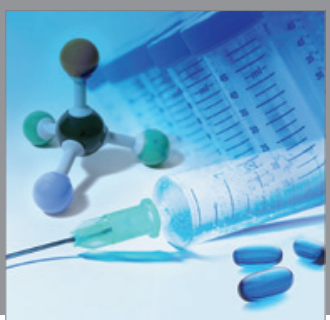

International Journal of

Medicinal Chemistry

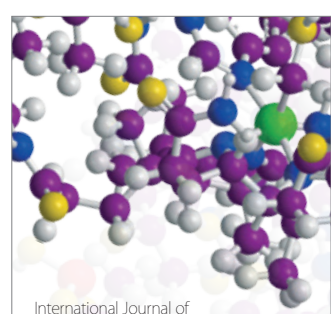

Carbohydrate Chemistry

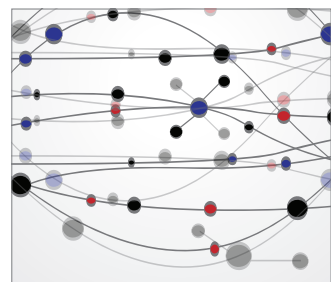

The Scientific World Journal
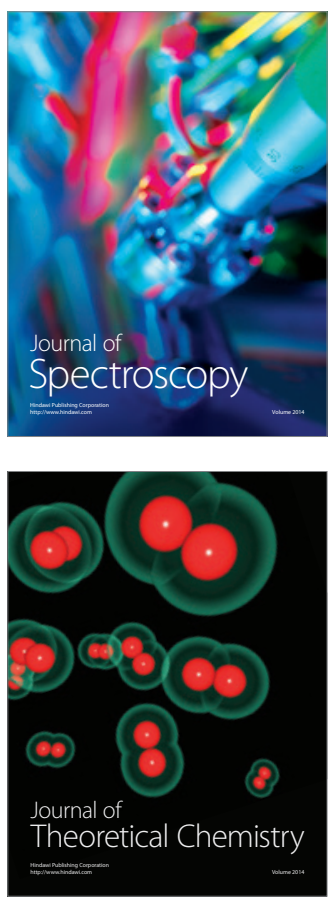
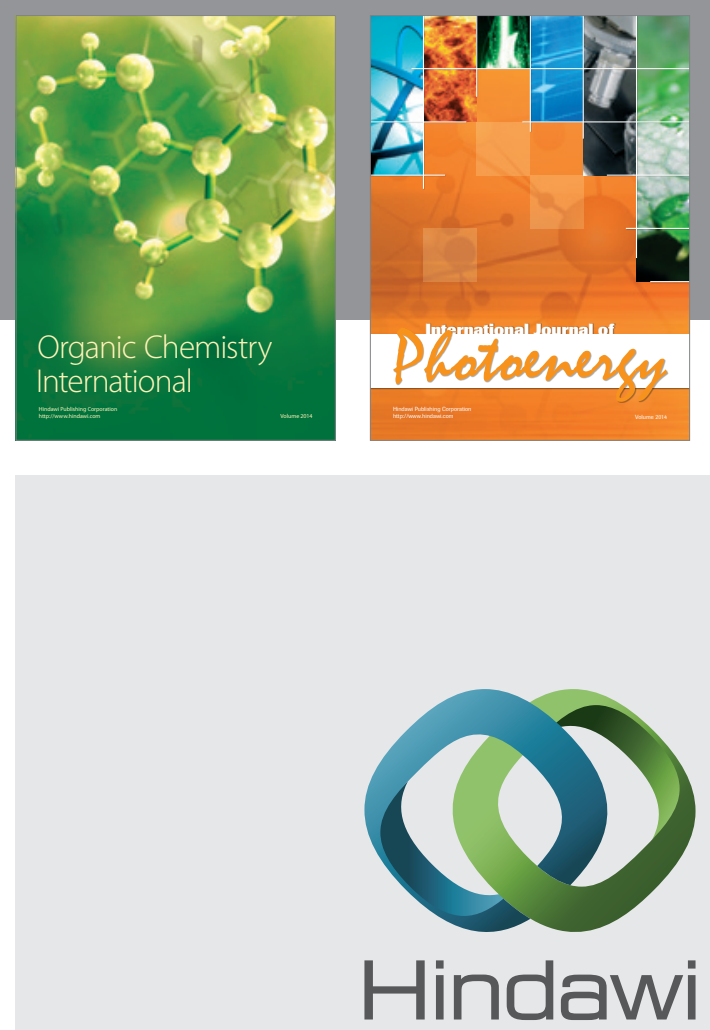

Submit your manuscripts at

http://www.hindawi.com
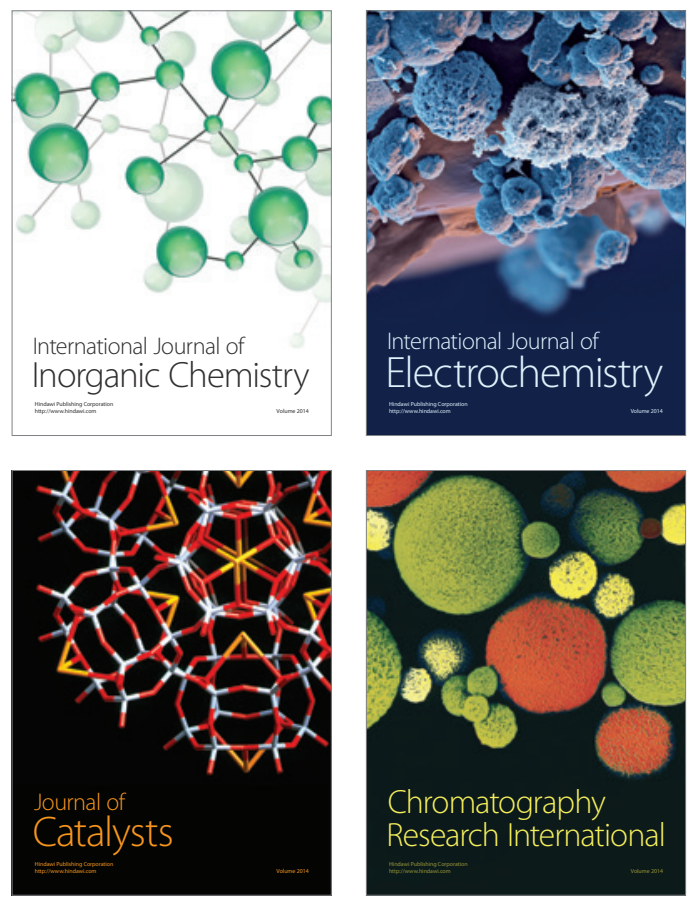
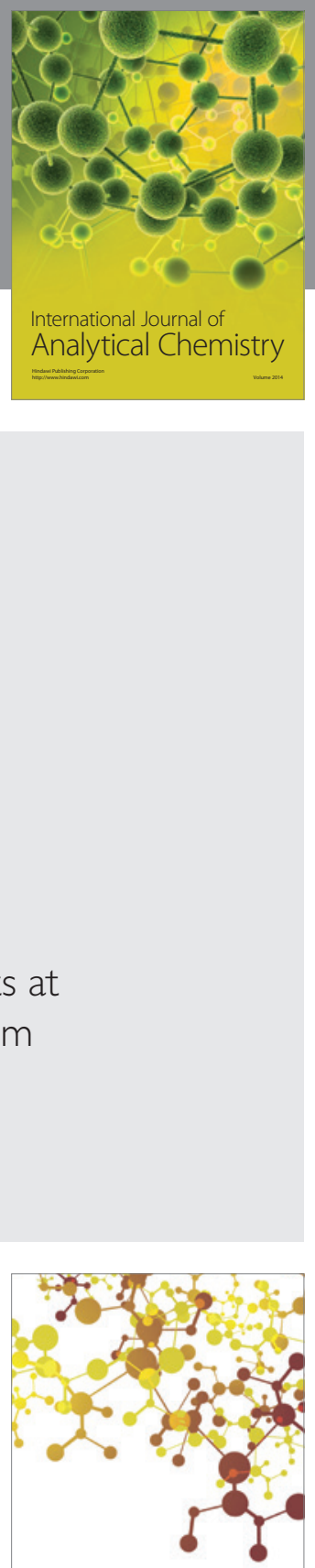

Journal of

Applied Chemistry
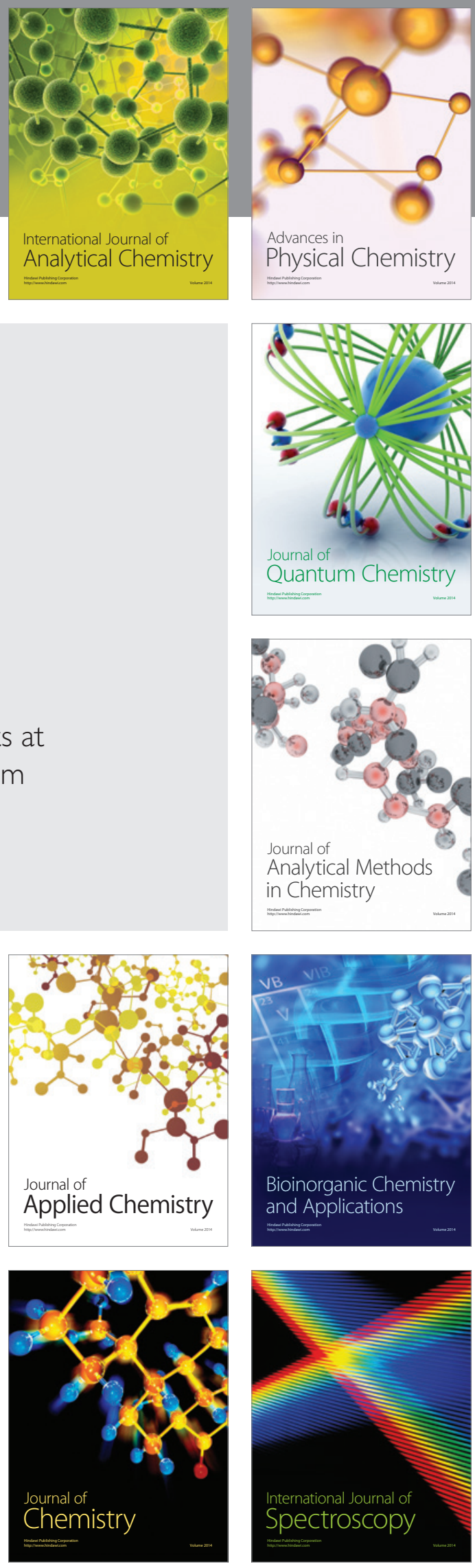